\title{
Spatiotemporal Changes of Urban Rainstorm-Related Micro-Blogging Activities in Response to Rainstorms: A Case Study in Beijing, China
}

\author{
Nan Wang ${ }^{1,2}\left(\mathbb{D}\right.$, Yunyan Du ${ }^{1,2, *}$, Fuyuan Liang ${ }^{3}$, Jiawei $\mathrm{Yi}^{1,2}$ and Huimeng Wang ${ }^{1,2} \mathbb{C}$ \\ 1 State Key Laboratory of Resources and Environmental Information System, Institute of Geographic Science \\ and Natural Resources Research, Chinese Academy of Sciences, Beijing 100101, China; \\ wangnan171@mails.ucas.edu.cn (N.W.); yijw@1reis.ac.cn (J.Y.); wanghm@1reis.ac.cn (H.W.) \\ 2 University of Chinese Academy of Sciences, Beijing 100101, China \\ 3 Department of Earth, Atmospheric, and Geographic Information Sciences, Western Illinois University, \\ Macomb, IL 61455, USA; F-Liang@wiu.edu \\ * Correspondence: duyy@lreis.ac.cn; Tel.: +8610-64888973
}

Received: 18 September 2019; Accepted: 26 October 2019; Published: 31 October 2019

check for updates

Featured Application: This paper examines rainstorm-related micro-blogging activities in response to rainstorms in an urban environment at fine spatial and temporal scales. Results could be used in supporting disaster assessment and mitigation decision making.

\begin{abstract}
Natural disasters cause significant casualties and losses in urban areas every year Further, the frequency and intensity of natural disasters have increased significantly over the past couple of decades in the context of global climate change. Understanding how urban dwellers learn about and response to a natural hazard is of great significance as more and more people migrate to cities. Social media has become one of the most essential communication platforms in the virtual space for users to share their knowledge, information, and opinions about almost everything in the physical world. Geo-tagged posts published on different social media platforms contain a huge amount of information that can help us to better understand the dynamics of collective geo-tagged human activities. In this study, we investigated the spatiotemporal distribution patterns of the collective geo-tagged human activities in Beijing when it was afflicted by the "6-22" rainstorm. We used a variety of machine learning and statistical methods to examine the correlations between rainstorm-related microblogs and the rainstorm characteristics at a fine spatial and a fine temporal scale across Beijing. We also studied factors that could be used to explain the changes of the rainstorm-related blogging activities. Our results show that the human response to a disaster is very consistent, though with certain time lags, in the virtual and physical spaces at both the grid and city scales. Such a consistency varies significantly across our study area.
\end{abstract}

Keywords: social media; rainstorm event; spatiotemporal analysis; factor assessing

\section{Introduction}

Natural disasters such as hurricanes, floods and tornadoes can cause significant life losses, property damages, and even political instability [1-4]. In the context of global climate change, natural disasters have become more frequent and pose increasing physical, social, and economic threats to human society $[5,6]$. Closely monitoring how a natural disaster disturbs human activities is thus of great value [7-9], particularly in an urban environment where human-environment relationships are usually much more complicated. 
Different methods and datasets have been used to study urban dwellers' response to a natural disaster. A comprehensive evaluation model was built to evaluate the macro-population vulnerability in response to an earthquake at city and county levels [10]. Questionnaire data were used to examine the impacts of bushfires on residents [11]. Qualitative studies have been conducted to examine how communities are resilient to the impacts of natural disasters using interview data [12].

Natural disasters usually pose significant threats to the dwellers being inflicted. The threats vary dynamically. Consequently, people's emotion and public opinions to such threats may also change rapidly [13]. Such dynamic changes couldn't be timely captured and examined using the afore-mentioned conventional methods and data. Unfortunately, the dynamic changes of the human response to a disaster are extremely important in disaster evaluation and mitigation.

The emerging social media data have shown their usefulness in tracking human behaviors in response to natural disasters and emergencies. Nowadays, Twitter, Facebook, Flicker and Weibo have become indispensable platforms for people to share their ideas and disseminate vital information in time [14-16], in particularly when a natural disaster, public safety event, or disease infection event occurs [17-21]. Data collected through these platforms have been used in improving situation awareness [22-24], event detection [25,26], communication analysis $[27,28]$ and even helping governments guide the public opinions $[29,30]$.

Social media data have also been used to detect and monitor the ongoing development of disasters such as influenza transmission, floods, typhoons, hurricanes, and terrorist attacks [31-34]. Different social media data have been examined to reveal the different development stages of a disaster and how human response to the development stages [35-37]. A research framework was constructed to extract multidimensional (time, space, content, and network) information from social data [8]. Disaster-related information derived from social media data was also used to examine the spatiotemporal impacts of a disaster on human activities and assess the actual disaster-induced damages [38-40]. A variety of machine learning methods have also been used to examine social media data to evaluate the disaster-induced damages [41,42].

Many studies have shown that public opinions in the virtual space, as reflected by social media data, is consistent with what happens in the real world at a broad geographical scale. Such consistency has not been sufficiently examined and clearly illustrated at a finer temporal and spatial scale. There is also a need to study the factors driving the human response to a disaster, particularly in an urban environment. In this study, we investigated how dwellers in a mega city react to rainstorms as revealed by blogging activities on Weibo, one of the most popular social media platforms in China. We then explored various factors that may contribute to the blogging activities in response to rainstorms.

\section{Study Area and Data}

\subsection{Study Area}

This study examined Weibo users' blogging activities in response to the rainstorms that hit Beijing from 21 to 24 June 2017, we chose the main urban area of Beijing as the study area as shown in Figure 1 (The water ponding points and major hubs in the main urban area have been marked in the Figure 1). Beijing is the capital of China. It significant grew over the past decade. The percent of the developed land in Beijing increases from $7.9 \%$ in 2005 to $16.3 \%$ in 2015. The total population has increased from 1538 million in 2005 to 2170.5 million in 2015. Beijing is also one of the most economically active cities in China with a total GDP of $\$ 975$ billion in 2005 to $\$ 3270$ billion in 2015.

Dwellers in Beijing use a variety of social media platforms on a daily base. Sina Weibo is one of the most popular platforms that allow people to stay in touch and share each other information about any on-going events. As of 2018, Sina Weibo has 462 million active users in China and every day an average 1.30 million words are posted online through it [42]. 


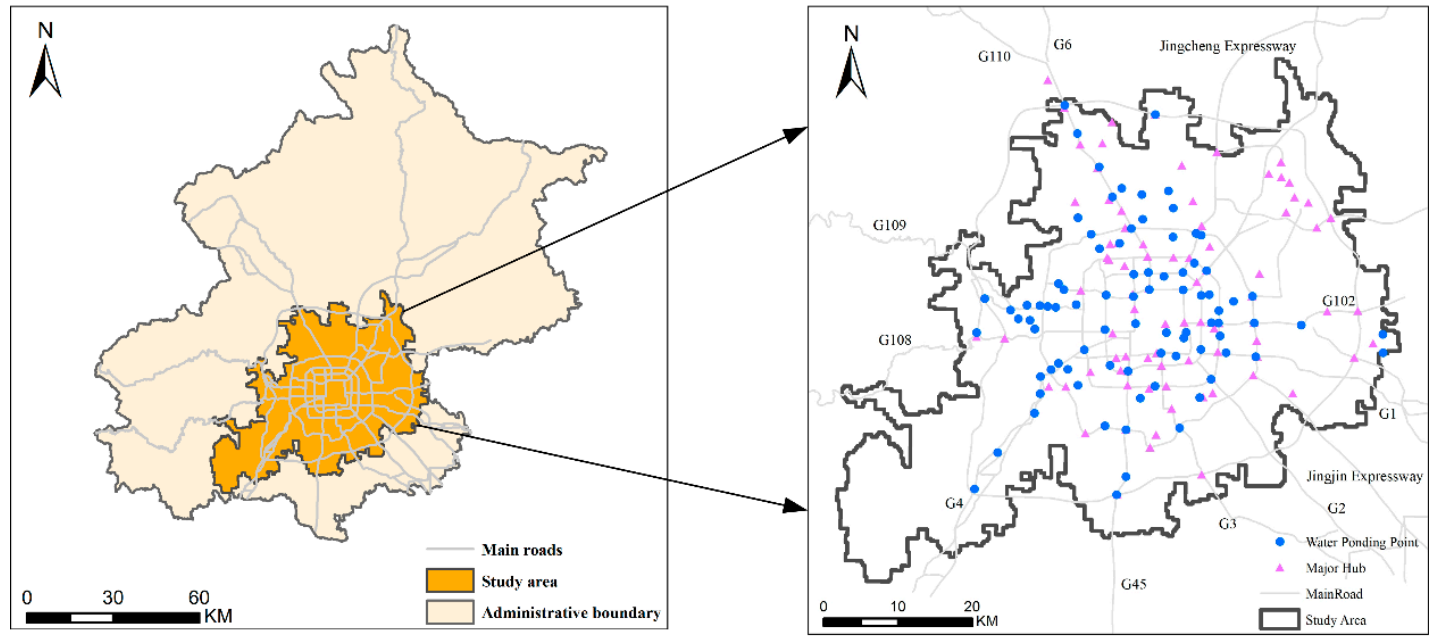

(a) (b)

Figure 1. A map showing the boundary of our study area. Location of the study area in Beijing (a) and overview of the study area $(\mathbf{b})$.

\subsection{Data}

A total of 3.32 million Weibo blogs geotagged with Beijing were crawled from the Sina Weibo platform. All posts were published from June to September 2017, a period that Beijing receives most of the rains all over the year. Every blog comes with the information of its user, publishing location, publishing time, and texts.

We also collected data of rainfall amount, points of interest (POIs), and water ponding sites. We used two precipitation data sets in this study. The hourly precipitation data at meteorological stations were collected from the China Meteorological Data Network (http://data.cma.cn/). The 1-h cumulative precipitation dataset was generated from the meteorological radar in Daxing, a town located $13 \mathrm{~km}$ south of the city. The radar covers the entire Beijing area and provides precipitation data with a spatial resolution of $1.051 \times 1.051 \mathrm{~km}$ (After image processing and registration processing). In this paper, we unified the study of grid scale to this resolution, and the other data sources used are also processed to this resolution for further analysis and processing.

The POIs include the locations of businesses, educational institutions, residential areas, transportation facilities, open spaces, and others. The data set was produced mainly for navigation by the Beijing NavInfo Co., Ltd, Beijing, 110000. Each POI comes with its coordinates (latitude and longitude), type, name, address and flag (show its importance level). In this paper, we categorized the POIs into five classes (Table 1).

Table 1. Summary statistics of the POIs.

\begin{tabular}{ccc}
\hline POI Class & Abbreviations & Total Numbers \\
\hline Common Service and Education Culture & CE & $1,402,310$ \\
Residential & R & 977,745 \\
Business & B & $6,695,615$ \\
Scenic area and Green Open Space & S & 264,065 \\
Transportation facilities & T & 299,360 \\
\hline
\end{tabular}

\section{Methods}

Figure 2 shows our data processing and analysis processes. We first used ArcGIS 10.5 to aggregate geotagged Weibo posts to grids with the same resolution $(1.051 \times 1.051 \mathrm{~km})$ as of the rainfall data. We used the support vector machine (SVM) model to classify and extract rainstorm-related microblogs. We then analyzed how city dwellers respond to the rainstorms in terms of the changes of the numbers 
of rainstorm-related microblogs at the grid scale and city scale. Finally, we investigated the factors that could be used to explain the city dwellers' response to the rainstorms.

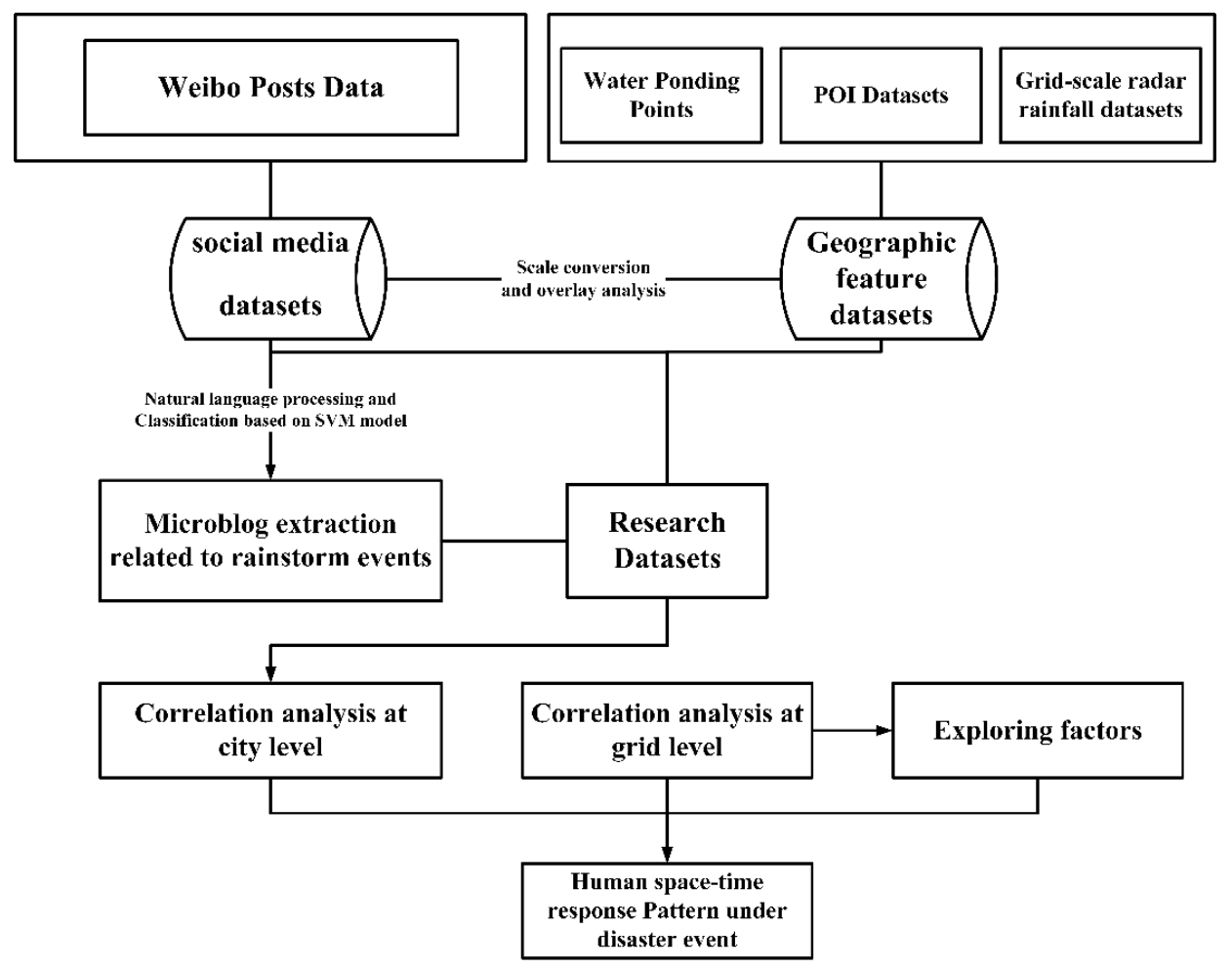

Figure 2. A flowchart showing the data processing and analysis processes.

\subsection{Extraction of Rainstorm-Related Weibo Posts}

In total we crawled 3.32 million Weibo posts that were published from June to September in 2017 and geo-tagged with city Beijing. We then used the keywords such as thunderbolt, storm, water, and rainfall to filter and found around 8000 posts that are possibly related to the rainstorms.

We then randomly selected 2000 out of the 8000 posts and manually checked each post. The post was labeled with "true" if it is truly related to a rainstorm otherwise "false" if it is not. The 2000 manually labeled posts were then evenly divided into two subsets, which were used to train the SVM classifier and validate the classification results, respectively.

The SVM classifier has been used in previous studies to label the microblogs either as event-related or event-independent $[18,43]$. It is a nonlinear classifier that was generated using the radial basis function (RBF). Essentially, it produces an optimal hyperplane that can best separate the rainstorm-related posts from those none-related. The hyperplane is defined by two parameters, $C$ and gamma, which represent the influencing range of a single sample and the influencing degree of the support vector, respectively. The two parameters were calculated using the GridSearchCV method [44] based on the training data subset. The validation subset data was then used to evaluate the separation accuracy using the five-fold cross validation method [45]. In this study, we obtained an F-score of 0.85, which indicates that the SVM classifier could be used to identify the truly-rainstorm-related Weibo posts. The final SVM model was then used to examine all unlabeled Weibo posts. In total we found 6072 out of the 8000 posts were truly rainstorm-related during the period of June to September 2017.

\subsection{Weibo Blogging Index}

We used two indexes to measure the blogging activities in response to the rainstorms. The first index, the human's event response index (HERI), is defined as the ratio between the standardized number of the rainstorm-related Weibo posts (RRWP) to the standardized total number of the posts 
within a specific cell (In the data standardization process, we normalize the total number of Weibo posts and RRWP to $0-1$ for each grid.).

$$
H E R I=\frac{\text { Standardized number of the RRWP }}{\text { Standardized total number of Weibo Posts }}
$$

The HERI could be used to measure human response intensity. A higher HERI value would indicate city dwellers are more active in blogging the rainstorms. A very similar index was used to estimate hazard-induced damages and monitor the post-hazard recovery speed $[40,46]$.

The HERI could be significantly affected by the rainfall amount. Thus, we used another index, the event normalized response relation (ENRR), to evaluate the human response to a rainstorm by eliminating the bias introduced by the variations in rainfall amount. The ENRR is expressed as the relationship between the HERI and the rainfall levels per cell. Both the HERI and rainfall amount values were first broken into three levels (high, medium, and low) using the Jenks Natural Breaks classification method, which clusters data into different classes by seeking to reduce the variance within a class and maximize the variance between classes. The different combinations of the three $H E R I$ and rainfall levels would reflect how dwellers response to a rainstorm which brings different rainfall amount across our study area. Figure 3 shows the nine relationships represented by ENRR. In the study, we mapped the relationship of ENRR to each grid to reflect the relationship between $H E R I$ and rainfall intensity in different regions.

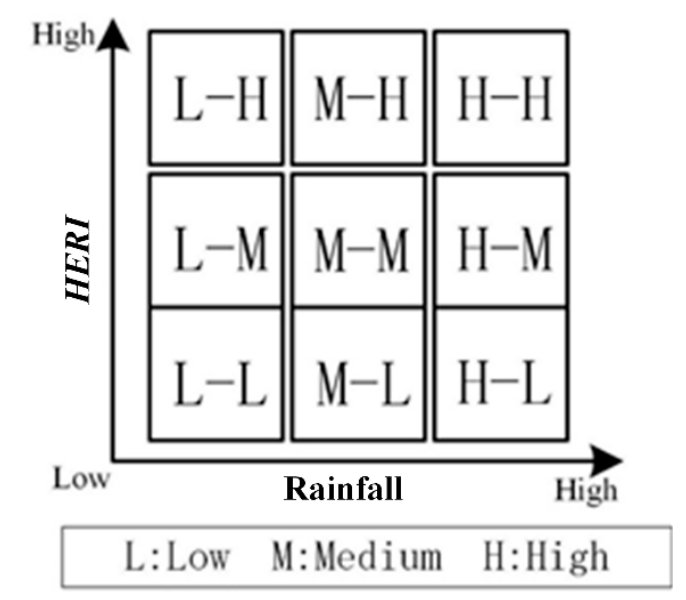

Figure 3. The 9 relationships of ENRR.

\subsection{Statistical Analysis}

We used a variety of conventional and spatial statistics methods to evaluate the areal difference of the blogging activities in response to the rainstorms across our study area. The hourly rainfall and the corresponding hourly RRWP were separately divided into four different groups according to their quartile levels, from which a confusion matrix was constructed. We then used the weighted Kappa coefficient to evaluate the consistency of the relationship between different levels of rainfall and the RRWP.

Quantile regression was used to estimate the conditional quantiles $(0.05,0.25,0.50,0.75,0.9$, and 1$)$ of the number of posts in response to certain rainfall amount by measuring their central tendency and statistical dispersion. Quantile regression could more accurately describe the variation range of the dependent variable in response to the dependent variable. We then used the receiver operating characteristic (ROC) curves $[47,48]$ to obtain the range within which the water ponding sites and major transportation hubs affect the blogging activities in response to the rainstorm. An optimal threshold is obtained by weighting both the sensitivity and the specificity equally, as measured by the closest distance between the points along the ROC curves and the top-left point, i.e., the perfect classification 
where the sensitivity and specificity both equal to 1 . In addition, we also performed hotspot analysis based on the HERI and the ENRR.

In this paper, we examined the blogging activities in response to the rainstorms at both city and grid levels, respectively. The city extent is defined by the administrative boundary of Beijing. Within the city, the rainfall and Weibo posts were aggregated to individual grids of $1.051 \mathrm{~km} \times 1.051 \mathrm{~km}$. There are 2776 grids within our study area, covering a total area of $2749.23 \mathrm{~km}^{2}$.

\section{Analysis and Results}

Five heavy rainstorms hit Beijing on 22 June, 6 July, 20 July, 2 August, and 22 August (Figure 4). The 22 June rainstorm brought historical record precipitation, flooded the city, and caused significant economic losses. When the city was afflicted by the 22 June rainstorm, Weibo users posted over 1000 blogs, the maximum blog number among all rainstorm events that hit Beijing in summer 2017. In this study, we mainly focus on the blogging activities in response to the 22 June rainstorm.

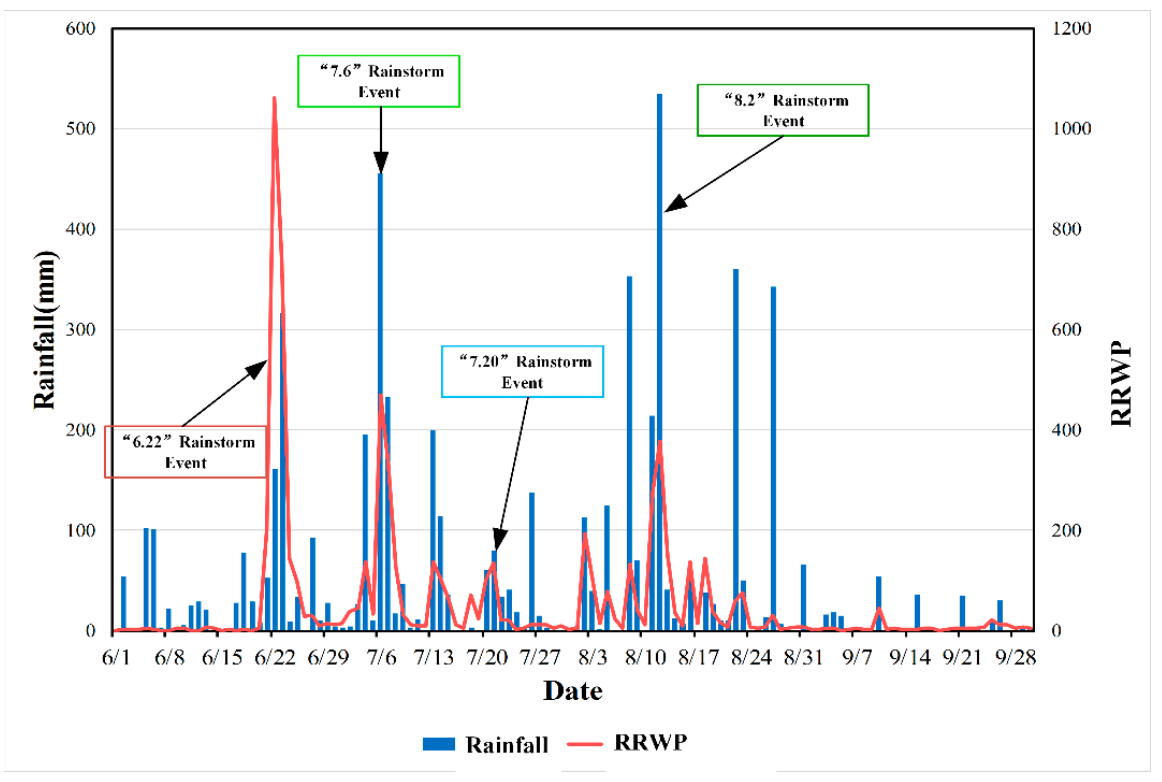

Figure 4. The time series RRWP and rainfall in Beijing from June to September 2017.

\subsection{The "622" Rainstorm}

At 16:00 on 21 June 2017, the Beijing Meteorological Bureau issued the first yellow lightning storm warning of a high altitude and low vortex, which later evolved into the 22 June rainstorm. The rainstorm first brought rain to the western part of Beijing from noon on 21 June and then across the whole Beijing city (Figure 5a). The storm lasted for $66 \mathrm{~h}$ and finally ended at 06:00 on 24 June. Heavy rains and floods were reported in Fangshan, Shunyi, Yanqing and Changping Districts. The storm flooded 131.5 hectares of agricultural land, affected 8594 people, and caused about $\$ 3.22$ million direct economic losses.

Both conventional and online medias covered this rainstorm extensively and generated a large number of news reports and Weibo posts. In total, we crawled 230,125 geotagged Weibo posts during the time period (20-27 June 2017) (Figure 5b) and 2362 out of them are RRWP (Figure 5c). 


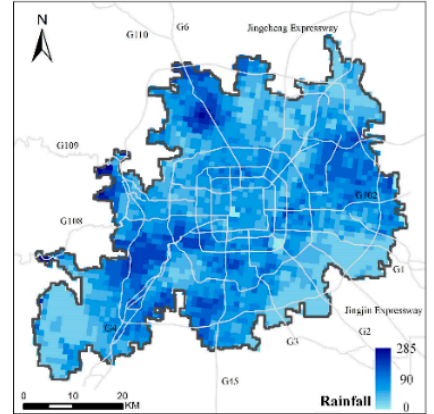

(a)

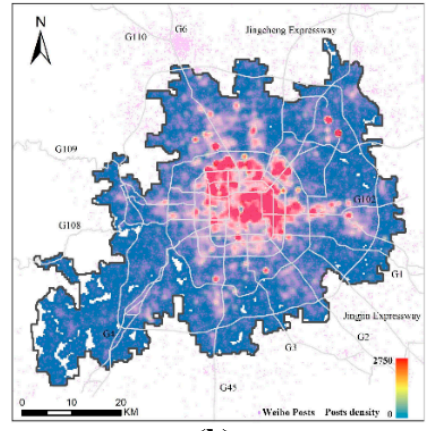

(b)

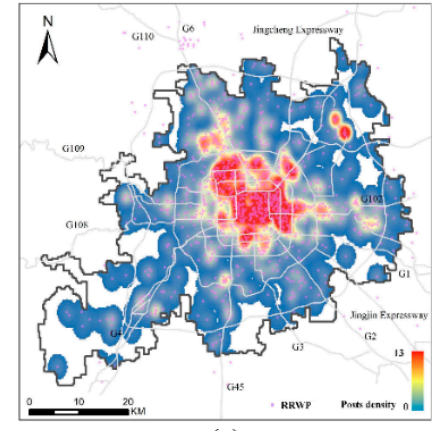

(c)

Figure 5. Spatial distribution of the rainfall amount (a), the number of Weibo posts (b), and the number of RRWP (c).

\subsection{Blogging Activities at City Level}

Figure 6 shows the time series hourly rainfall and the hourly number of RRWP from 20 to 28 June. No RRWP was found on the social media platform before the rainstorm hit the city. Rainstorm-related blogging activities were first detected when the first rainstorm warning was issued at 4:20 p.m. on 21 June. The blogging activities significantly intensified, particularly when the rainstorm is most intensive during the time period from 19:00 on 21 June to 04:00 on 24 June. During this time period, the city rainfall amount accounts for $90.5 \%$ of the total rainfall brought to Beijing by the " 6.22 " rainstorm. About $91.6 \%$ of the RRWP was posted during this time period.

Figure 6 also shows that variations in the rainfall amount are generally consistent with the blogging activities though there seems to be a 1-h time lag. The blogging activities are most intense in about $10 \mathrm{~min}$ before the release of the rainstorm warning. A high rainfall amount is not always accompanied by strong blogging activities, particularly when raining occurs from the late night to the early morning and the rainstorm hits suburbs with a small population flow.

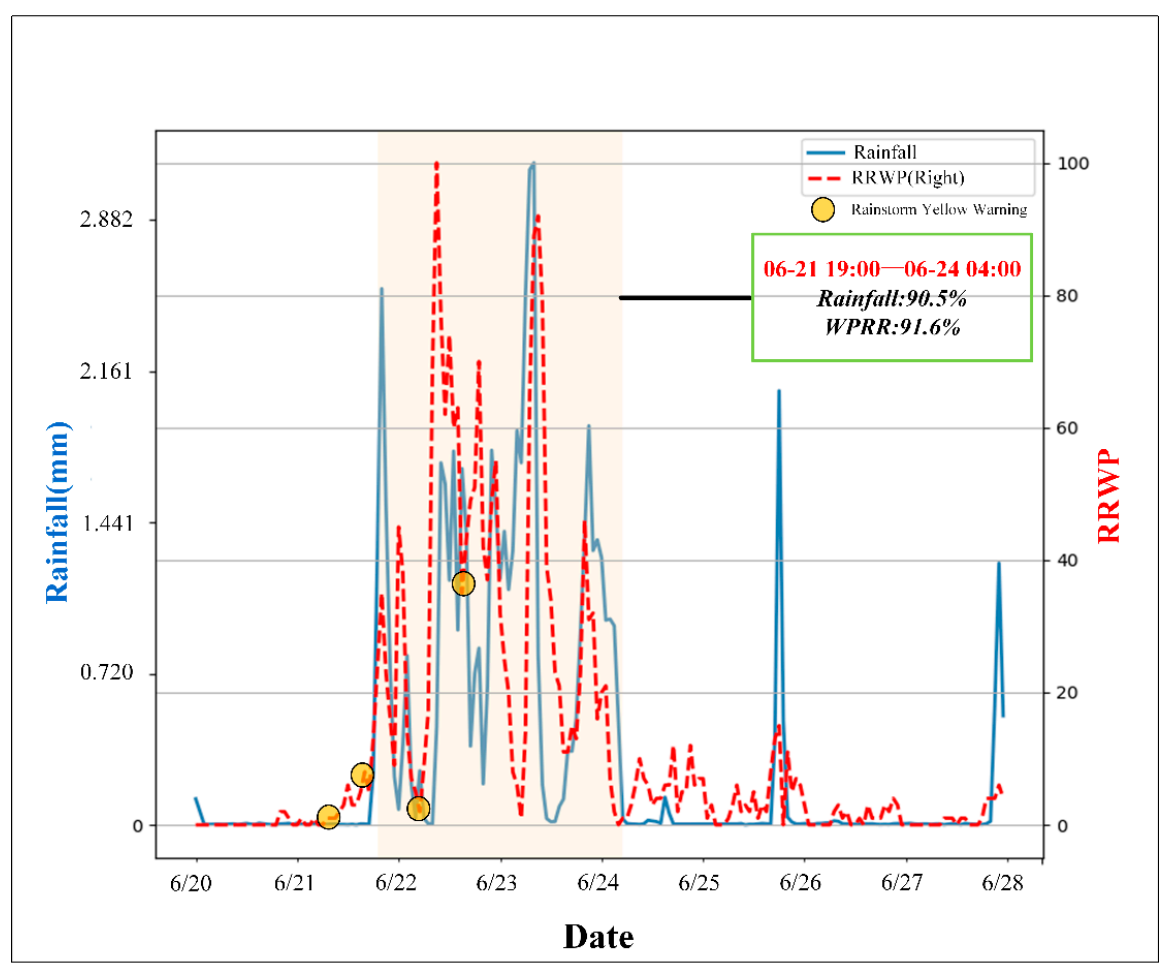

Figure 6. Time series of hourly accumulated rainfall and Weibo posts. 
The confusion matrix (Figure 7) between the different levels of rainfall amount and the RRWP shows that higher rainfall levels are always associated with more RRWP. We found $38 \mathrm{~h}$ with higher rainfall amount and more RRWP. Lower rainfall levels are associated with fewer RRWP. A statistically significant weighted Kappa coefficient of 0.63 indicates that the levels of blogging activities are consistent with the rainfall levels across the city.

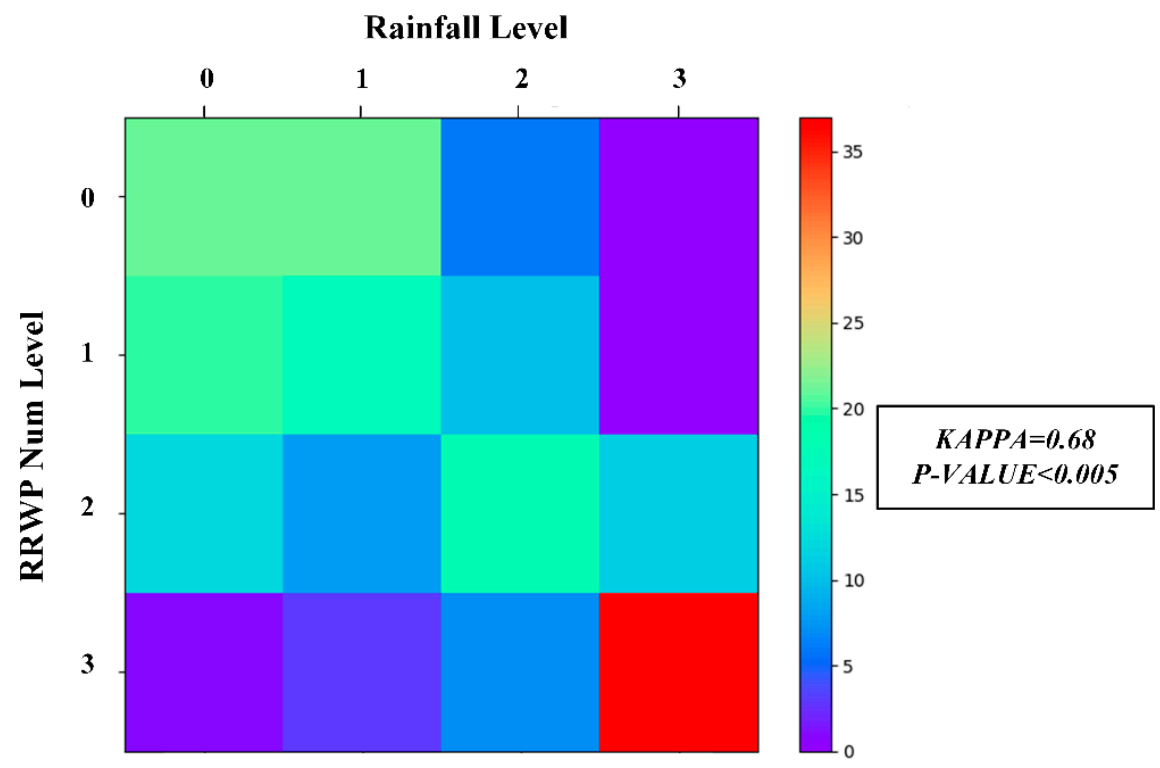

Figure 7. Consistency between rainfall and RRWP levels.

Figure 8 shows the correlation coefficients between the number of RRWP and rainfall amount with a time lag up to $6 \mathrm{~h}$. With increased time lags, the coefficients drop though the correlations are statistically significant at a confidence level of 0.01 . The highest coefficient 0.653 was found when the time lag is $1 \mathrm{~h}$, suggesting that more RRWP were posted one hour after the rainstorm. In other words, heavy rainfall usually triggers intensified blogging activities one hour later. It seems that, after $1 \mathrm{~h}$ of the rainstorm, the city starts to be afflicted by issues such as waterlogging and traffic congestion. Such issues tend to intensify rainstorm-related blogging activities.

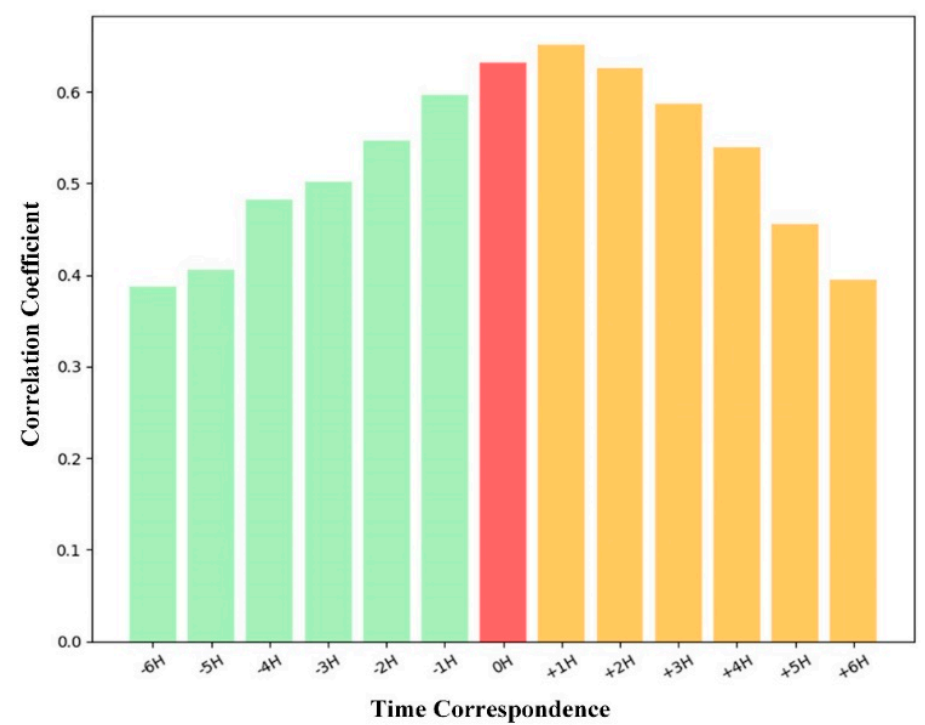

Figure 8. Correlation coefficients between the rainfall amount and the number of RRWP with different time lags. 
Quantile regression analysis between the rainfall amount and the number of RRWP (Figure 9) shows a steeper slope for the higher percentile data. In other words, increased rainfall shows a more significant impact on the number of RRWP when the rainfall is heavier. By contrast, when the rainfall is less than $30^{\text {th }}$ percentile (the average rainfall of the grid in the study area is 8.6), an increase in the rainfall amount shows little impacts on the change of the RRWP. Once the rainfall exceeds the $30^{\text {th }}$ percentile, the RRWP starts to increase. As the rainfall percentile increases, the regression slope becomes steeper. In other words, once the rainfall is over the $30^{\text {th }}$ percentile, it tends to trigger Weibo users to post much more RRWP.
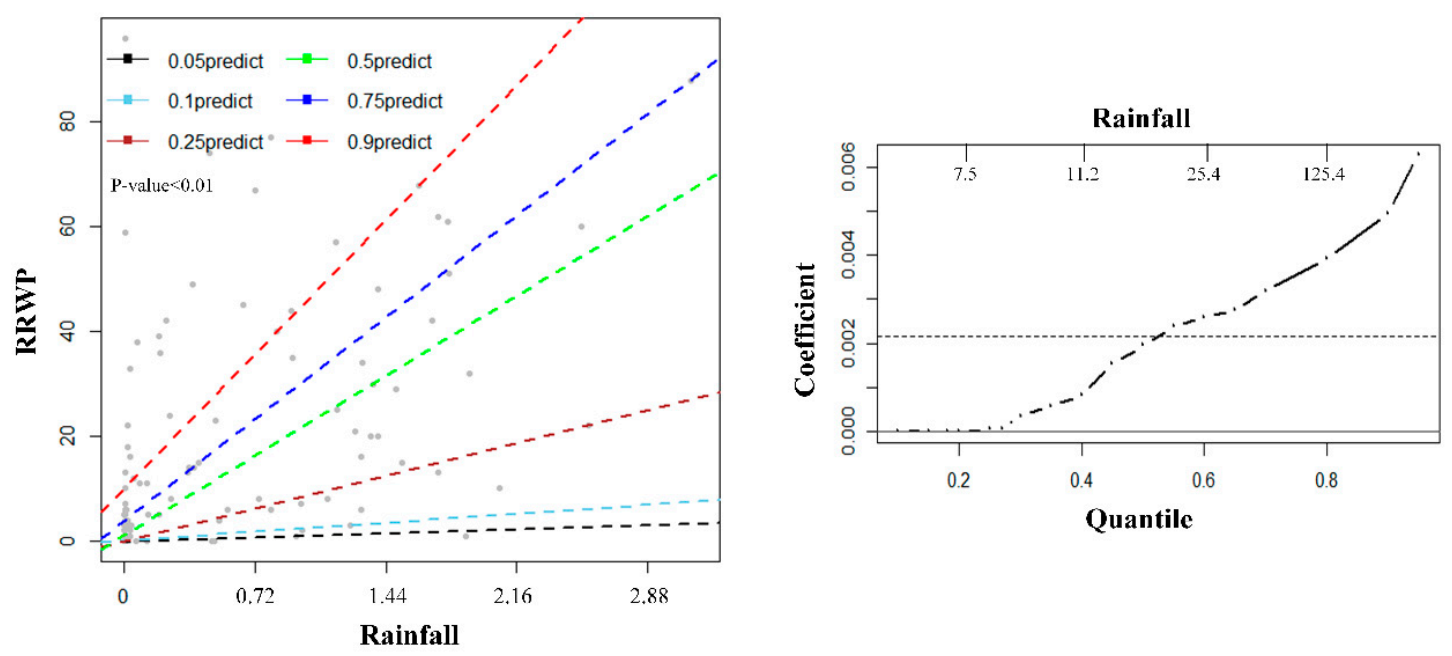

Figure 9. Quantile regression estimates of the relationship between the RRWP and the rainfall amount at the city scale.

\subsection{Human Response at Grid Scale}

In order to explore the differences in human response intensity of different time periods at grid scale, we first divided the whole day into four time periods $(08-10,11-16,17-20,21-07)$, and then map the RRWPs in different time periods by the 4 time periods' dot maps. Figure 10 shows the results. We can find that in the study area, the morning rush hours (08-10) and the evening rush hours (17-20) have the strongest human response intensity. During these two periods, important transportation hubs (Commercial business center, large jobs-housing area) and water ponding point areas have become regions with a high response in the main urban area of Beijing. In addition, there was a phenomenon in which dense points are distributed around the subway and along important roads. The occurrence of rainstorm event has caused great obstacles to traffic operation and delayed human's travel. The points in the second period (11-16) are mainly distributed near the traffic station and the more severely affected areas. The points in the last period are sparsely distributed in the study area. We also found the density distribution of four periods' points in major traffic stations such as airports, railway stations, and bus stations were relatively uniform, while large jobs-housing areas are densely distributed at points of the morning rush hours and the evening rush hours.

Figure 11 shows the correlation between the rainfall amount and the number of RRWP at the grid scale. The correlation coefficients vary between -0.14 and 0.86 with an average of 0.22 . The negative or no correlation relationship is mainly found in suburbs, such as the Changping, Huairou and Miyun Districts. By contrast, higher correlation coefficients are mainly found in populated areas within the city, including populated residential communities, important transportation hubs, and areas significantly impacted by the rainstorms as shown in news reports. 


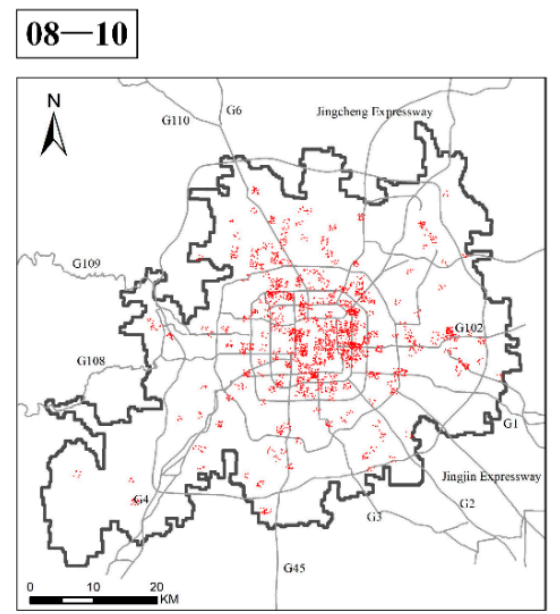

\section{$17-20$}

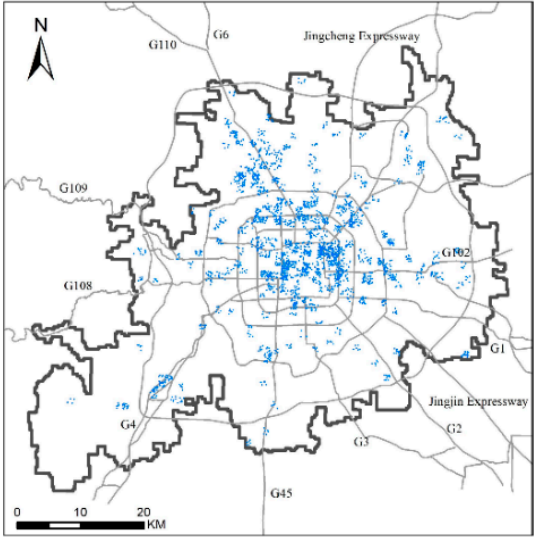

$$
11-16
$$

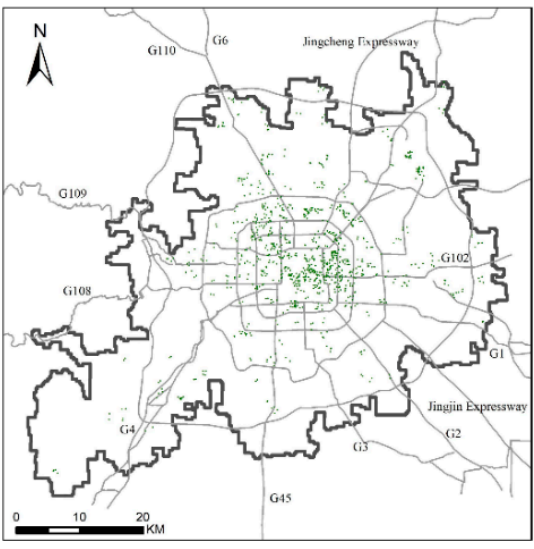

$21-07$

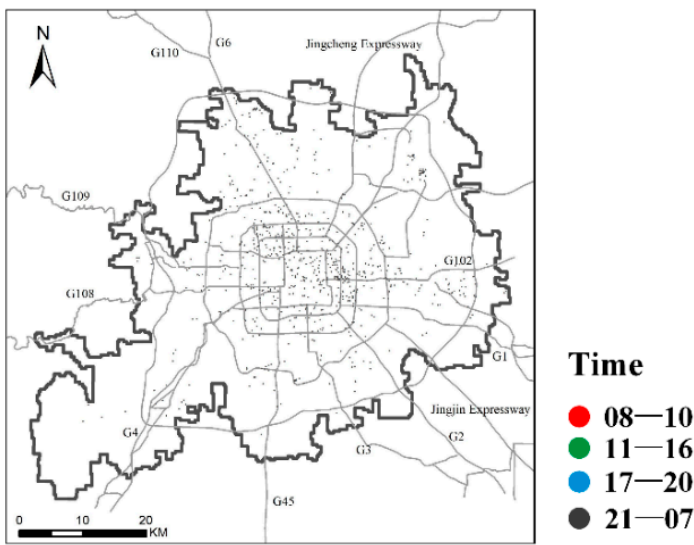

Figure 10. Dot maps of in different time periods based on grid cells.

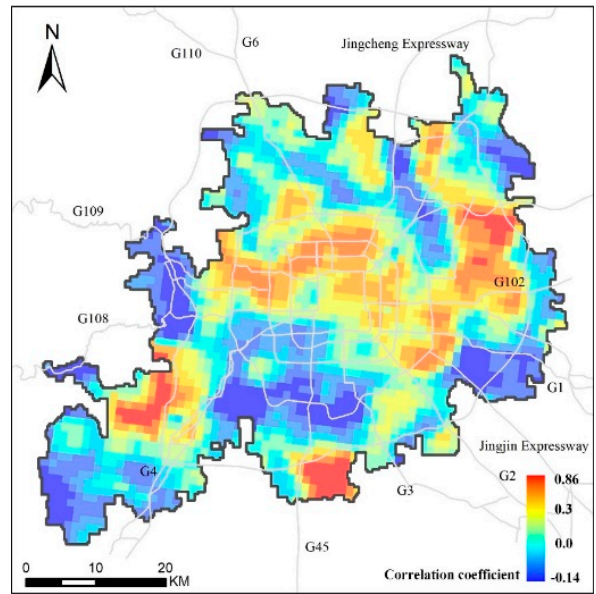

Figure 11. Correlation coefficients at grid level across our study area.

Figure 12a shows the HERI across our study area. Only the 2203 grids with at least 10 daily Weibo posts are selected to calculate the HERI. At the grid scale, HERI values range between 0 and 9.83 with an average value of 1.23 .

The regions with a higher HERI value are mainly found in three places in our study area. The first are the areas with more rainstorm-induced damages, including serious house collapse, road blockage and mudslides. These areas are mainly found in the suburbs such as the Fangshan and Mentougou 
Districts. The densely populated regions, including Zhongguancun and the CBD, the Tongzhou residential area, an Internet technology parks also have a higher HERI value. Regions with important transportation hubs also have a higher HERI value. The transportation hubs include subway stations, train stations, and airports.

Figure $12 \mathrm{~b}$ shows the HERI hotspot analysis results. Hotspots are mainly located in densely populated areas, important residential and workplaces, such as the Tongzhou residential area, CBD districts, and IT parks. It is worth noting that a large number of hotspots are found in the urban core areas. By contrast, the cold spots are mainly found in the remote suburbs of our study area. Such areas have a low population thus limited human activities.

The proportions of POIs within each hotspot identified are shown in Figure 12c. The HERI hotspots in the Beijing Capital Airport, Yizhuang, and Changping-Shahe Districts have the highest percent of transportation POIs. The texts of the RRWP within these hotspots show that the rainstorms may significantly delay the commute in these regions thus stimulate users to publish more RRWP to complain the traffic. The hotspots in the Tongzhou residential area and the Mentougou District show a higher proportion of residential POIs. Hotspots in Zhongguancun, Chaoyang CBD and IT Park have a highly mixture of multiple types of residential, business, and education POIs. There is no significant difference in the proportions of the POIs in other hotspots.

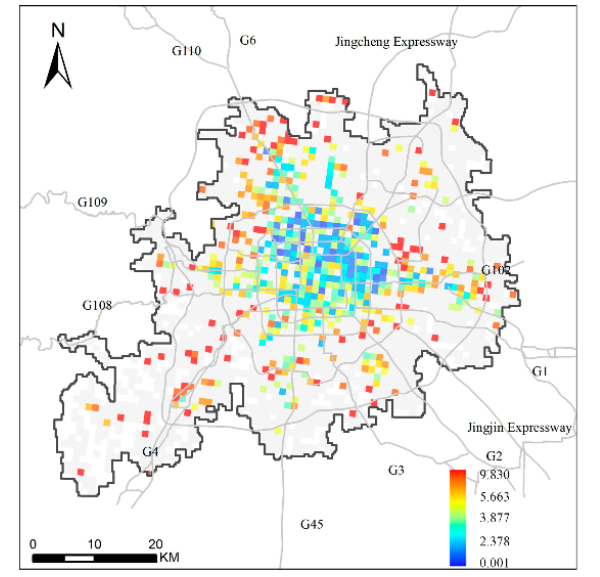

(a)

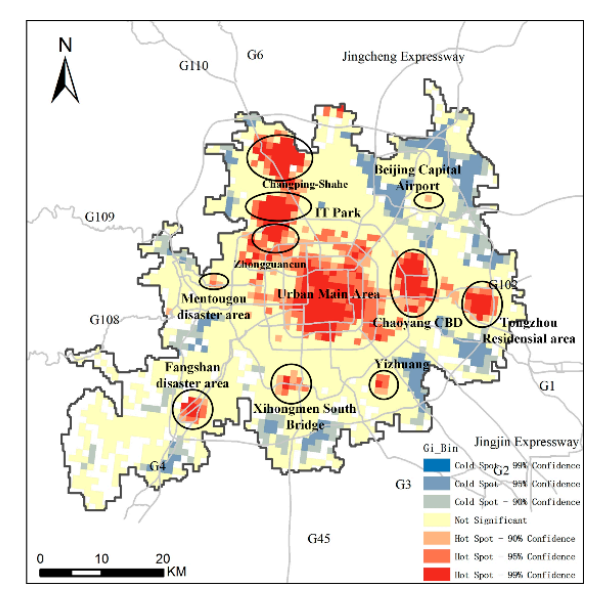

(b)

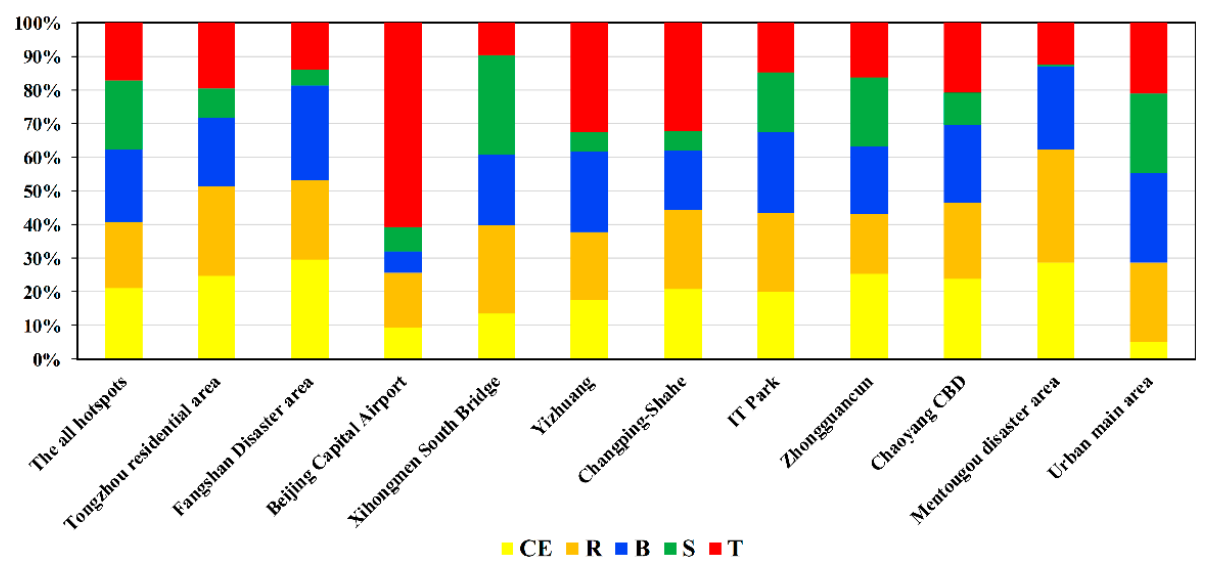

(c)

Figure 12. Spatial distribution of the HERI values (a); HERI hotspot analysis results (b); Percentage of POI types in each HERI hotspot area (c).

Figure 13a shows the binary relationship between the different levels of HERI and rainfall amounts. We classify the HERI and rainfall amount into three groups (high, medium, and low) using the Jenks 
natural breaks, respectively. In total, there would be nine combinations between the different levels of HERI and rainfall amounts. The HH combination (high HERI and more rainfall) is located in suburbs, such as Fangshan District and $\mathrm{Xi}^{\prime}$ erqi, which were hit by heavy rains and afflicted with serious rainstorm-induced damages and losses. The combination (HL) with a higher HERI and less rainfall is mainly found in densely populated areas, including the urban core area, Tongzhou District, CBD and the Beijing Capital Airport. The texts of the RRWP show that people in these areas complain that the rainstorms caused significant traffic jams and ruined their daily routine. Passengers trapped in the Beijing Capital Airport also published more RRWP due to the significant flight delays. The LH combination (low HERI and high rainfall amount) is mainly in the sparsely populated regions, where few RRWP were posted due to the fewer number of the Weibo users.

Figure $13 b$ shows the POI types in the different combinations of the HERI and rainfall amount levels. The areas with a higher HERI value tend to have more transportation POIs, no matter what the rainfall amount is. By contrast, places with fewer RRWP and higher rainfall levels are less populous and with more green space.

(a)

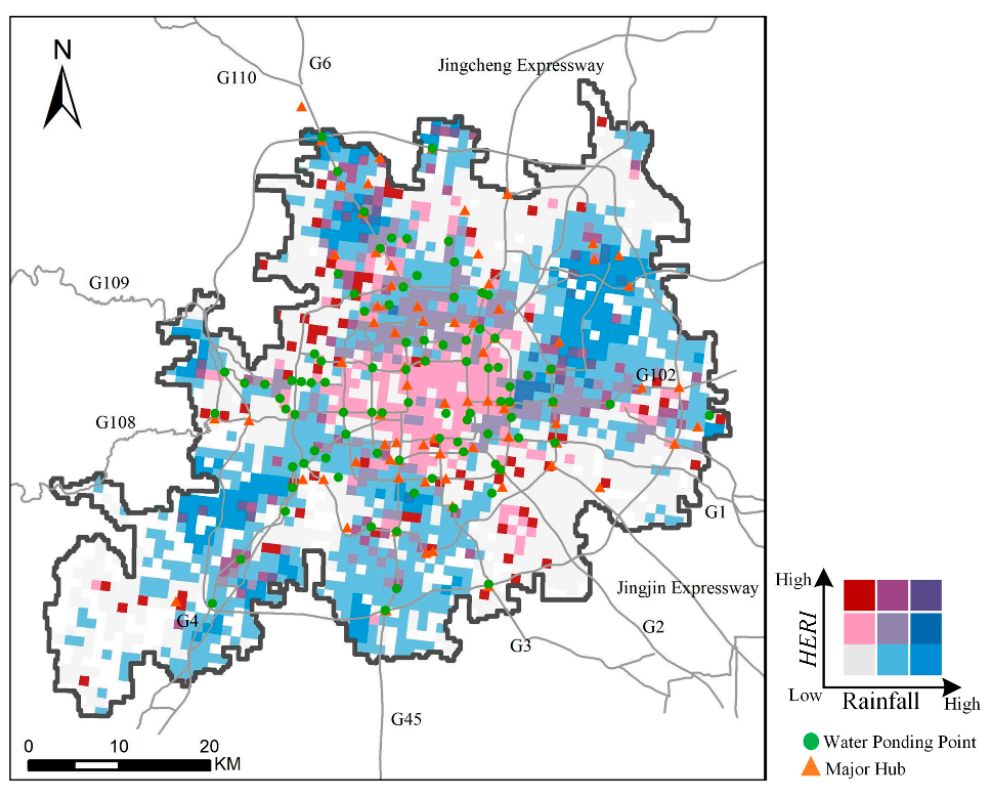

(b)

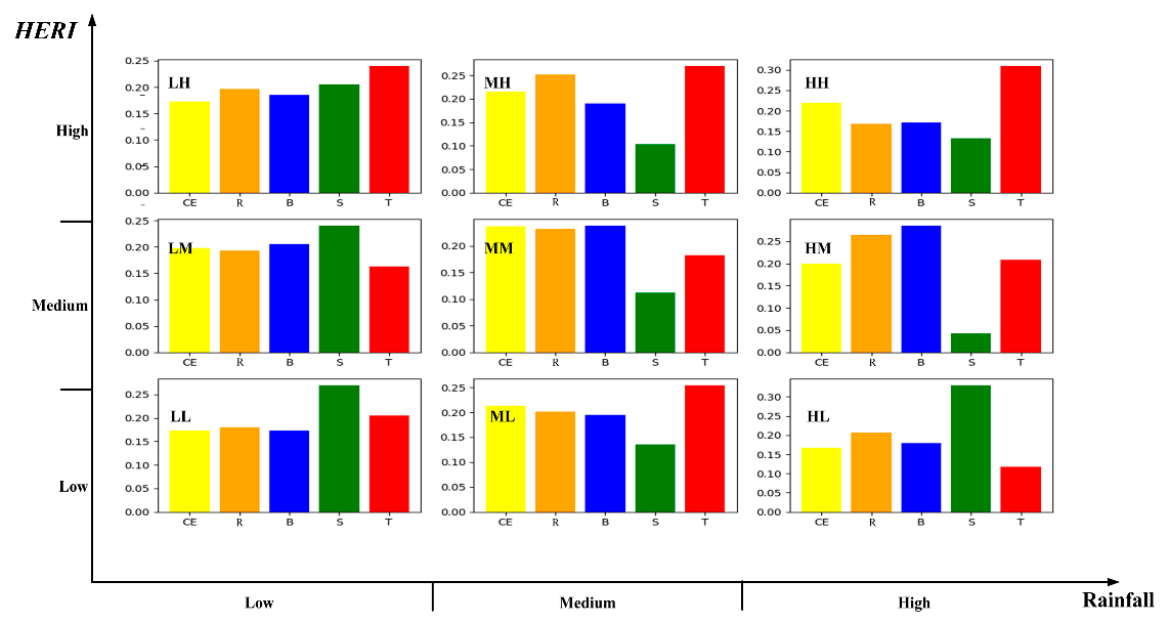

Figure 13. The ENRR values across our study area (a) and the proportions of different types of POIs within the areas with different ENRR values (b). 


\subsection{Factors Influencing HERI}

For all grids across our study area, the AUC values on the ROC curves are 0.767 and 0.733 for the water ponding sites and the major transportation hubs, respectively (Figure 14). The most appropriate OIDF values for the afore-mentioned two factors are $3400 \mathrm{~m}$ and $3200 \mathrm{~m}$ respectively. The bilateral Welch $t$ test results show that the HERI value of the areas within the OIDF distance of a water ponding site and a major transportation hub were both significantly higher than those beyond and the difference is statistically significant at the 0.01 significance level.

Table 2 shows the number and density of water ponding sites and major transportation hubs by each level combination of rainfall amount and RRWP. The level combinations with intense blogging activities are all associated with high density of water ponding sites and major transportation hubs, no matter what the rainfall amount is. By contrast, the level combinations with inactive blogging activities are associated with a low density of water ponding sites and major transportation hubs.

Table 2. The statistics of water ponding sites and transportation hubs by different ENRR categories.

\begin{tabular}{cccccc}
\hline \multirow{2}{*}{ ENRR } & \multirow{2}{*}{ Area $\left(\mathbf{k m}^{\mathbf{2}} \mathbf{)}\right.$} & \multicolumn{2}{c}{ Water Ponding Points } & \multicolumn{2}{c}{ Major Transportation Hubs } \\
\cline { 3 - 6 } & & Number & Density & Number & Density \\
\hline $\mathrm{L}_{\mathrm{R}} \mathrm{L}_{\mathrm{P}}$ & 915 & 35 & 3.8 & 25 & 2.7 \\
ML & 702 & 29 & 4.1 & 14 & 2.0 \\
$\mathrm{HL}$ & 202 & 4 & 2.0 & 10 & 5.0 \\
$\mathrm{LM}$ & 228 & 27 & 11.8 & 17 & 7.5 \\
MM & 182 & 15 & 8.2 & 16 & 8.8 \\
$\mathrm{HM}$ & 19.4 & 3 & 15.5 & 1 & 5.2 \\
$\mathrm{LH}$ & 82.5 & 6 & 7.3 & 9 & 10.9 \\
MH & 79 & 11 & 13.9 & 6 & 7.6 \\
HH & 22.8 & 3 & 13.2 & 2 & 8.8 \\
\hline
\end{tabular}

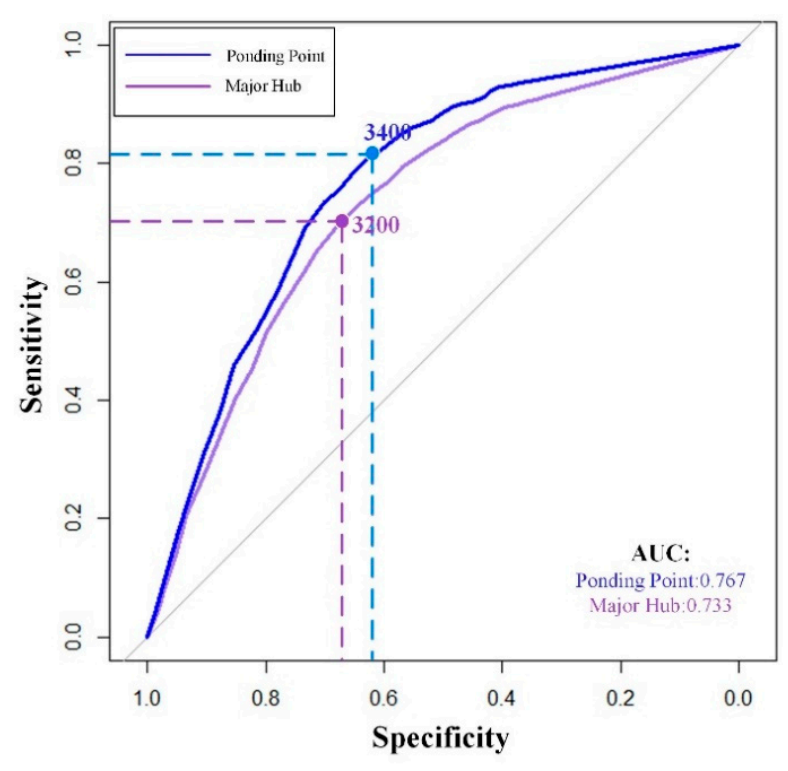

Figure 14. The ROC curves of the influencing factors.

\section{Conclusions}

In this study, we inferred the human activities from the rainstorm-related Weibo posts and examined how different levels of human activities are associated with different rainfall amount levels at both city and grid scales. The consistency between the rainfall amount and the human activities could be explained by the distribution of the water ponding sites and major transportation hubs. The regions with high density of water ponding sites and major transportation hubs tend to show intense human 
response to rainstorms in terms of the number of rainstorm-related Weibo posts. At different time periods, the intensity of human responses to rainstorm events in areas of different attributes and functions were also very different. The human response has been significantly enhanced during the early and late peak hours and is concentrated in important transportation hubs and water ponding sites. The occurrence of a rainstorm event has a huge impact on human travel. Analysis of the rainstorm-related posts suggests that there is no significant difference between the impacting ranging $(\sim 3.3 \mathrm{~km})$ of a water ponding site and a major transportation hub.

We found that on the large scale, although the ground disaster space has a high consistency with the social media space, the intensity of responses at different stages, different spatial areas, and during different time periods of the disaster on social media platform were different. When looking at spatial differences on a grid scale for urban disaster events, the impacts of different types of region vary greatly due to the complexity of human-land relationships. During a rainstorm, the existence of special areas such as urban water ponding points, traffic stations, main jobs and housing areas, important line sites, and some disaster sites have led to frequent occurrence of secondary disasters and become major concentrated areas where humans respond strongly. These results show that there are time and space differences in the human response at the urban scale and grid scale under urban rainstorm events. Our research on the spatial consistency is similar to the previous research conclusions $[36,39,49]$, but a further exploration of fine spatiotemporal process and supplementation of the factors affecting the differences in human responses give us a new understanding of the human-land relationship under the event conditions at a fine scale.

Of course, this study has some defects that can be ameliorated by additional research to improve upon our framework and further research goals. This study only examined the number of rainstorm-related Weibo posts without considering other information available in the original Weibo posts, such as the emotions, themes, and characteristics of the social media information. Other multi-source spatial data such as the nighttime lights, ambient population data, and road traffic congestion data, if successfully integrated, could provide a more comprehensive study on the human response to a natural disaster. The integration of multi-source spatial data and more comprehensive data mining methods would also significantly reduce the uncertainty of the associations between human activities in both the physical and virtual spaces.

Author Contributions: Conceptualization, N.W. and Y.D.; methodology, N.W.; validation, N.W., Y.D., H.W., and F.L.; formal analysis, N.W.; investigation, N.W.; resources, N.W and J.Y.; data curation, J.Y.; writing-original draft preparation, N.W.; writing-review and editing, F.L.; visualization, N.W.; supervision, Y.D.; project administration, Y.D.; funding acquisition, Y.D.

Funding: This research was funded by the National Key Research and Development Program of China (Grant Nos. 2017YFB0503605 and 2017YFC1503003), and the Strategic Priority Research Program of the Chinese Academy of Sciences (Grant Nos. XDA20040401 and QYZDY-SSW-DQC007-2), and the National Mountain Flood Disaster Investigation Project (SHZH-IWHR-57).

Conflicts of Interest: The authors declare no conflict of interest.

\section{References}

1. Klomp, J.; Valckx, K. Natural disasters and economic growth: A meta-analysis. Glob. Environ. Chang. 2014, 26, 183-195. [CrossRef]

2. Cole, S.A.; Healy, A.; Werker, E. Do Voters Appreciate Responsive Governments? Evidence from Indian Disaster Relief. Soc. Sci. Electron. Publ. 2012, 97, 167-181. [CrossRef]

3. Parenton, F.V.J. Disaster and Aftermath: Selected Aspects of Individual and Group Behavior in Critical Situation. Soc. Forces 1959, 38, 129-135.

4. Ramseur, J.L. Oil Spills in U.S. Coastal Waters: Background, Governance, and Issues for Congress; Congressional Research Service Reports; Library of Congress, Congressional Research Service: Washington, DC, USA, 2010.

5. Aalst, M.K.V. The Impacts of Climate Change on the Risk of Natural Disasters. Disasters 2006, 30, 5-18. [CrossRef] [PubMed] 
6. Mendelsohn, R.; Emanuel, K.; Chonabayashi, S.; Bakkensen, L. The impact of climate change on global tropical cyclone damage. Nat. Clim. Chang. 2012, 2, 205-209. [CrossRef]

7. Goodchild, M.F. Citizens as sensors: The world of volunteered geography. GeoJournal 2007, 69, $211-221$. [CrossRef]

8. Wang, Z.; Ye, X. Social media analytics for natural disaster management. Int. J. Geogr. Inf. Sci. 2017, 32, 1-24. [CrossRef]

9. Liu, Y.; Liu, X.; Gao, S.; Gong, L.; Kang, C.G.; Zhi, Y.; Chi, G.H.; Shi, L. Social Sensing: A New Approach to Understanding Our Socioeconomic Environments. Ann. Assoc. Am. Geogr. 2015, 105, 512-530. [CrossRef]

10. Linet, Ö.; Ekinci, E.; Beste, K. Emergency Logistics Planning in Natural Disasters. Ann. Op. Res. 2004, 129, 217-245.

11. De, V.P.; Guilbert, N.; Mesple-Somps, S. Impact of Natural Disasters on Education Outcomes: Evidence from the 1987-89 Locust Plague in Mali. J. Afr. Econ. 2015, 24, 57-100.

12. Nie, C.J.; Yang, L.S.; Li, H. Macro Assessment of Seismic Population Vulnerability in China. Progress Geogr. 2012, 31, 375-382.

13. Khunwishit, S. Community Resilience in Thailand: A Case Study of Flood Response in Nakhonsawan City Municipality; University of North Texas: Denton, Texas, 2013.

14. Morss, R.E.; Wilhelmi, O.V.; Meehl, G.A.; Dilling, L. Improving Societal Outcomes of Extreme Weather in a Changing Climate: An Integrated Perspective. Ann. Rev. Environ. Resour. 2011, 36, 1-25. [CrossRef]

15. Lazer, D.; Pentland, A.; Adamic, L. Computational Social Science. Science 2009, 323, 721-723. [CrossRef] [PubMed]

16. Vespignani, A. Predicting the Behavior of Techno-Social Systems. Science 2009, 325, 425-428. [CrossRef] [PubMed]

17. Bai, H.; Yu, G.A. Weibo-based approach to disaster informatics: Incidents monitor in post-disaster situation via Weibo text negative sentiment analysis. Nat. Hazards 2016, 83, 1177-1196. [CrossRef]

18. Li, Z.; Wang, C.; Emrich, C.T. A novel approach to leveraging social media for rapid flood mapping: A case study of the 2015 South Carolina floods. Cartogr. Geogr. Inf. Sci. 2017, 45, 97-110. [CrossRef]

19. Neppalli, V.K.; Caragea, C.; Squicciarini, A.; Tapia, A.; Stehle, S. Sentiment analysis during Hurricane Sandy in emergency response. Int. J. Disaster Risk Reduct. 2017, 21, 213-222. [CrossRef]

20. Cvetojevic, S.; Hochmair, H.H. Analyzing the spread of tweets in response to Paris attacks. Comput. Environ. Urban Syst. 2018, 71, 14-26. [CrossRef]

21. Chunara, R.; Andrews, J.R.; Brownstein, J.S. Social and News Media Enable Estimation of Epidemiological Patterns Early in the 2010 Haitian Cholera Outbreak. Am. J. Trop. Med. Hyg. 2012, 86, 39-45. [CrossRef]

22. Vieweg, S. Microblogging during two natural hazards events: What twitter may contribute to situational awareness. In SIGCHI Conference on Human Factors in Computing Systems; ACM: Museum, Singapore, 2010.

23. Caragea, C.; McNeese, N.; Jaiswal, A.; Traylor, G.; Kim, H.-W. Classifying text messages for the Haiti earthquake. In Proceedings of the 8th International Conference on Information Systems for Crisis Response and Management, New York, NY, USA, 20-23 May 2011.

24. Freeman, M. Fire, Wind and Water: Social Networks in Natural Disasters; IGI Global: Pennsylvania, NY, USA, 2011.

25. Stewart, K.; Glanville, J.L.; Bennett, D.A. Exploring Spatiotemporal and Social Network Factors in Community Response to a Major Flood Disaster. Prof. Geogr. 2014, 66, 421-435. [CrossRef]

26. Chae, J.; Thom, D.; Bosch, H. Spatiotemporal Social Media Analytics for Abnormal Event Detection using Seasonal-Trend Decomposition. In Proceedings of the IEEE Conference on Visual Analytics Science \& Technology, Seattle, WA, USA, 14-19 October 2012; IEEE Computer Society: Washington, DC, USA, 2012.

27. Dong, X.; Mavroeidis, D.; Calabrese, F. Multiscale event detection in social media. Data Min. Knowl. Discov. 2015, 29, 1374-1405. [CrossRef]

28. Brennan, S.; Sadilek, A.; Kautz, H. Towards understanding global spread of disease from everyday interpersonal interactions. In Proceedings of the twenty-third international joint conference on artificial intelligence, Beijing, China, 3-19 August 2013; AAAI Press: Beijing, China, 2013; pp. 2783-2789.

29. Magdy, W.; Darwish, K.; Abokhodair, N. Quantifying Public Response towards Islam on Twitter after Paris Attacks. arXiv 2015, arXiv:1512.04570.

30. Berger, L. Local, National and Global Islam: Religious Guidance and European Muslim Public Opinion on Political Radicalism and Social Conservatism. West Eur. Politics 2016, 39, 205-228. [CrossRef] 
31. Kryvasheyeu, Y.; Chen, H.; Obradovich, N. Rapid assessment of disaster damage using social media activity. Sci. Adv. 2016, 2, e1500779. [CrossRef] [PubMed]

32. Fohringer, J.; Dransch, D.; Kreibich, H. Social media as an information source for rapid flood inundation mapping. Nat. Hazards Earth Syst. Sci. 2015, 15, 2725-2738. [CrossRef]

33. Takahashi, B.; Tandoc, E.C.; Carmichael, C. Communicating on Twitter during a disaster: An analysis of tweets during Typhoon Haiyan in the Philippines. Comput. Hum. Behav. 2015, 50, 392-398. [CrossRef]

34. Rosser, J.F.; Leibovici, D.G.; Jackson, M.J. Rapid flood inundation mapping using social media, remote sensing and topographic data. Nat. Hazards 2017, 87, 103-120. [CrossRef]

35. Houston, J.B.; Hawthorne, J.; Perreault, M.F. Social media and disasters: A functional framework for social media use in disaster planning, response, and research. Disasters 2014, 39, 1-22. [CrossRef]

36. Kryvasheyeu, Y.; Chen, H.; Moro, E. Performance of Social Network Sensors during Hurricane Sandy. PLoS ONE 2015, 10, e0117288. [CrossRef]

37. Zou, L.; Lam, N.S.N.; Cai, H. Mining Twitter Data for Improved Understanding of Disaster Resilience. Ann. Am. Assoc. Geogr. 2018, 108, 1-20. [CrossRef]

38. Wu, D.; Cui, Y. Disaster early warning and damage assessment analysis using social media data and geo-location information. Decis. Support Syst. 2018, 111, 48-59. [CrossRef]

39. Yago, M.; Li, Z.; Cutter, S.L. Leveraging Twitter to gauge evacuation compliance: Spatiotemporal analysis of Hurricane Matthew. PLoS ONE 2017, 12, e0181701.

40. Resch, B.; Florian, U.; Havas, C. Combining machine-learning topic models and spatiotemporal analysis of social media data for disaster footprint and damage assessment. Cartogr. Geogr. Inf. Sci. 2017, 45, 362-376. [CrossRef]

41. Weibo User Development Report for 2018. Available online: https://data.weibo.com/report/reportDetail?id= 433 (accessed on 15 May 2019).

42. Zahra, K.; Ostermann, F.O.; Purves, R.S. Geographic variability of Twitter usage characteristics during disaster events. Geo-sp. Inf. Sci. 2017, 20, 231-240. [CrossRef]

43. Aramaki, E.; Maskawa, S.; Morita, M. Twitter Catches the Flu: Detecting Influenza Epidemics Using Twitter; Emnlp: AsiaWorld-Expo, Hong Kong, China, 2011.

44. Dilrukshi, I.; Zoysa, K.D.; Caldera, A. Twitter news classification using SVM. In Proceedings of the International Conference on Computer Science \& Education, Kuala Lumpur, Malaysia, 29 November-1 December 2013; IEEE: Piscataway, NJ, USA, 2013.

45. Zhang, H.; Chen, L.; Qu, Y. Support Vector Regression Based on Grid-Search Method for Short-Term Wind Power Forecasting. J. Appl. Math. 2014, 2014, 1-11. [CrossRef]

46. Gao, Y.; Wang, S.; Padmanabhan, A. Mapping spatiotemporal patterns of events using social media: A case study of influenza trends. Int. J. Geogra. Inf. Sci. 2018, 32, 425-449. [CrossRef]

47. Hanley, J.A.; Mcneil, B.J. The meaning and use of the area under a receiver operating characteristic (ROC) curve. Radiology 1982, 143, 29-36. [CrossRef]

48. Cook, N.R. Use and Misuse of the Receiver Operating Characteristic Curve in Risk Prediction. Circulation 2007, 115, 928-935. [CrossRef]

49. Wang, Y.; Wang, T.; Tsou, M.-H. Mapping Dynamic Urban Land Use Patterns with Crowdsourced Geo-Tagged Social Media (Sina-Weibo) and Commercial Points of Interest Collections in Beijing, China. Sustainability 2016, 8, 1202. [CrossRef]

(C) 2019 by the authors. Licensee MDPI, Basel, Switzerland. This article is an open access article distributed under the terms and conditions of the Creative Commons Attribution (CC BY) license (http://creativecommons.org/licenses/by/4.0/). 